\title{
28 Research Square \\ Growth Retardation Caused by Reduced Tonoplast V-ATPase Activity in Arabidopsis thaliana
}

\author{
Guihong Liang \\ Hunan Agricultural University \\ Dong Liu \\ Hunan Agricultural University

\section{Yan Xiao} \\ Hunan Agricultural University

\section{Tianjiao Tang} \\ Hunan Agricultural University \\ Haixing Song \\ Hunan Agricultural University \\ Zhenhua Zhang ( $\sim$ zhzh1468@163.com ) \\ https://orcid.org/0000-0002-8877-1090
}

\section{Research article}

Keywords: proton pumps, vacuole, nitrate, cation homeostasis, potassium

Posted Date: January 6th, 2020

DOI: https://doi.org/10.21203/rs.2.19978/v1

License: (c) (i) This work is licensed under a Creative Commons Attribution 4.0 International License.

Read Full License 


\section{Abstract}

Background: Vacuoles are unique compartments in plant cells. Their multiple functions require massive fluxes of molecules across their limiting membrane, the tonoplast. Transport across the tonoplast is energized by its membrane potential and the proton gradient established by two proton pumps, the vacuolar $\mathrm{H}^{+}$-ATPase (V-ATPase), and the vacuolar $\mathrm{H}^{+}$-pyrophosphatase (V-PPase), which play important roles in the growth and development of plants. However, the mechanisms by which they affect plant growth and development, in the absence of tonoplast proton pumps, remain unclear.

Results: In this study, we show that the Arabidopsis thaliana double mutant, vha-a2vha-a3, which lacks two tonoplast-localized isoforms of the membrane-integral V-ATPase subunit VHA-a, is viable, but shows a phenotype of inhibited growth and leaf chlorosis. Reduced total nitrogen absorption and increased nitrate assimilation lead to the accumulation of ammonium in the shoot, which results in the growth retardation of vha-a2vha-a3. Concurrently, the distribution and concentration of cations are abnormal in plants when $\mathrm{VHA}-\mathrm{a} 2$ and $\mathrm{VHA}-\mathrm{a} 3$ genes are absent, which is another major growth-limiting factor. Interestingly, the growth inhibition of the vha-a2vha-a3 double mutant was alleviated and senescence delayed, while the concentration of total nitrogen increased and that of ammonium decreased, when adding additional potassium.

Conclusions: Our results show that plants can be viable without $V H A-a 2$ and $V H A-a 3$ but are affected by multiple factors that result in growth retardation, which can be alleviated by adding additional potassium, which provides a new insight on the relationship between vacuolar $\mathrm{H}^{+}$-ATPase and potassium.

\section{Background}

The evolutionary success of higher plants is largely due to their unique cellular architecture [1]. Vacuoles, as the largest organelles in mature plant cells, accounting for about $90 \%$ of cell volume, contain a large amount of water and solutes that are necessary for plant growth and development [2-4]. The multiple functions of the vacuole require massive fluxes of molecules across its limiting membrane, the tonoplast. Transport of solutes across the tonoplast is energized by its membrane potential and the proton gradient established by two proton pumps, the vacuolar $\mathrm{H}^{+}$-ATPase (V-ATPase), and the vacuolar $\mathrm{H}^{+}$pyrophosphatase (V-PPase), which play important roles in the growth and development of plants [5-7].

The V-ATPase and the V-PPase use Mg.ATP and Mg.PPi as substrates, respectively. The combined activity of the two pumps causes protons to enter the vacuole from the cytoplasm, thereby forming an electrochemical gradient between the cytoplasm and vacuole and driving transport of compounds against their concentration gradient across the tonoplast. Both proton pumps are among the most abundant tonoplast proteins, indicating that the amount of energy spent in vacuolar transport is enormous $[8,9]$. V-ATPases are multi-subunit, highly conserved proton pumps that consist of two sub- 
complexes. The peripheral $\mathrm{V}_{1}$ complex is composed of eight subunits (VHA-A to $-\mathrm{H}$ ), which are exposed to the cytoplasmic side and are responsible for ATP hydrolysis. The membrane-integral $\mathrm{V}_{0}$ complex consists of six subunits (VHA-a, $-c,-c^{\prime}, c^{\prime \prime},-d$, and $-e$ ), which are integrated into the membrane, and act as a channel for translocation of protons from the cytoplasm into the lumen of endomembrane compartments. It also serves as the binding site for polymerization and assembly of $\mathrm{V}_{1}$ subunits $[10,11]$.

In Arabidopsis, three isoforms of the integral membrane subunit VHA-a have different sub-cellular locations: VHA-a1 is located in the trans-Golgi network/early endosome (TGN/EE), while VHA-a2 and VHA-a3 are located in the tonoplast [12]. The A. thaliana double mutant, vha-a2vha-a3, which lacks the two tonoplast-localized isoforms of the membrane-integral V-ATPase subunit VHA-a, is viable but exhibits severe growth inhibition and premature aging [4].

There are multiple types of ion transporters and channels in the tonoplast that transport $\mathrm{NO}_{3}{ }^{-}, \mathrm{Na}^{+}$, protons, and many other ions. The activity of proton pumps in the tonoplast provides a driving force for the active transport of various solutes. Nitrate, as an important plant nutrient, is allocated to the metabolic pool (cytoplasm) and the storage pool (vacuole) once it is absorbed by plant roots. The change in relative size of the two nitrate reservoirs is mediated by the $\mathrm{NO}_{3}{ }^{-} / \mathrm{H}^{+}$exchange channel CLCa in the tonoplast $[4,13]$, and is dependent on the activity of V-ATPase and V-PPase. These vacuolar proton pumps establish an electrochemical $\mathrm{H}^{+}$gradient across the tonoplast that energizes the transport of $\mathrm{NO}_{3}{ }^{-}$ against its concentration gradient. Ion balance is necessary for normal growth and development of plants, and the activity of proton pumps in vacuole membranes is crucial to the regulation of ion homeostasis in cells $[14,15]$. Membrane-bound transport systems regulating cytosolic ion homeostasis $\left(\mathrm{K}^{+}, \mathrm{Na}^{+}, \mathrm{Ca}^{2+}\right.$, and $\left.\mathrm{Fe}^{2+}\right)$ and ion accumulation in the vacuole are of crucial importance for adaptation to stress conditions [16].

Potassium $\left(\mathrm{K}^{+}\right)$is an essential macronutrient for plant growth and development [17]. $\mathrm{K}^{+}$is absorbed by plant roots and its transport is mediated by $\mathrm{K}^{+}$channels as well as high affinity $\mathrm{K}^{+}$transporters $[18,19]$, both in the plasma membrane and in the tonoplast of plant cells [16, 20, 21]. In addition to being the most abundant cation in higher plants, $\mathrm{K}^{+}$is crucial for plant nutrition, enzyme activities, ion homeostasis, and osmoregulation $[22,23]$. It is well established that $\mathrm{K}^{+} / \mathrm{NO}_{3}{ }^{-}$absorption and transport in vascular plants are somehow coordinated [24-27]. In addition, $\mathrm{K}^{+}$has a certain effect on alleviating the growth inhibition caused by ammonium toxicity; an increased $\mathrm{K}^{+}$supply or a restoration of $\mathrm{K}^{+}$transport can rapidly relieve $\mathrm{NH}_{4}{ }^{+}$toxicity $[28,29]$.

Decreases in proton pump activity affect the growth and development of plants [1, 4], but the contributing factors and metabolic mechanisms remain unknown. Here, we show that the A. thaliana double mutant, vha-a2vha-a3, which lacks the two tonoplast-localized isoforms of the membrane-integral V-ATPase subunit VHA-a, is viable, but shows a strong reduction in growth and nutrient storage capacity, accelerating the premature aging of mutant plants. Interestingly, the growth inhibition of the vha-a2vhaa3 double mutant was alleviated, senescence delayed, and, at the same time, total nitrogen (TN) was 
increased and ammonium was decreased when mutant plants were grown with additional $\mathrm{K}^{+}$. Taken together, our results show that plants without VHA-a2 and VHA-a3 can remain viable, but are affected by multiple factors, which result in growth retardation.

\section{Results}

V-ATPase activity at the tonoplast regulates growth and development

The seeds lacking VHA-a2 and VHA-a3 genes located in the tonoplast were obtained from the Krebs' laboratory and have been described previously [4]. In this study, the vha-a2vha-a3 double mutant displayed severe growth retardation and significant symptoms of premature aging, compared with wildtype (Fig. 1A), with the outcome of $74 \%$ reduction in biomass. The relative expression of the senescenceassociated gene 29 (SAG29) was up-regulated in the mutant when grown hydroponically for four weeks (Fig. 1B and C). Furthermore, compared with WT, leaf area, total length, surface area, root volume, and number of root tips and forks were reduced by $58 \%, 61 \%, 82 \%, 90 \%, 37 \%$, and $71 \%$, respectively, when the tonoplast V-ATPase activity decreased (Fig. S1). Accordingly, plants had poor growth when the VHA-a2 and VHA-a3 were absent.

Loss of tonoplast V-ATPase reduced nitrogen absorption

To investigate whether the absence of tonoplast V-ATPase activity would restrain the nitrogen absorption and inhibit growth, the total nitrogen (TN) accumulation and TN content of the vha-a2vha-a3 double mutant were determined (Fig. $2 \mathrm{~A}$ and B). TN content was significantly reduced by $9.7 \%$ compared to that of the wild-type. In addition, the relative expression of nitrate transporter 1.1 gene (NRT1.1) was downregulated by $25 \%$ in the tonoplast of the V-ATPase-deficient double mutant (Fig. 2C). Therefore, these data suggest that the severe inhibition of growth of the vha-a2vha-a3 mutant may be due to reduced total nitrogen uptake.

Disruption of nitrogen metabolism causes ammonium accumulation in shoots of the vha-a2vha-a3 double mutant

Previous results have shown that nitrogen uptake in the vha-a2vha-a3 mutant was reduced, which is one possible reason why the mutant displayed growth inhibition [4]. Nitrate, as an important nitrogen source, is allocated to the cytoplasm and vacuole once absorbed by plant roots [30]. Nitrate accumulation within the vacuole is primarily mediated by the $\mathrm{NO}_{3}{ }^{-} / \mathrm{H}^{+}$exchanger AtCLCa and is dependent on the $\mathrm{H}^{+}$gradient [31]. In accordance, we investigated if the reduced tonoplast V-ATPase activity led to a shift in the relative size of the two nitrate pools. To investigate this possibility, the nitrogen metabolites of $A$. thaliana shoots and roots were determined after four weeks' growth under hydroponic conditions. The results revealed that vha-a2vha-a3 mutants contained $61 \%$ less nitrate (Fig. 3A); at the same time, nitrate reductase (NR) activity increased to four times that of wild-type (WT) NR in shoots (Fig. 3B). Thus, the double mutant accumulated ammonium 45\% more than Col-0 (Fig. 3C) and induced higher glutamine synthetase (GS) levels in shoots (Fig. 3D). These conditions might be inhibitory to the growth of the vha-a2vha-a3 double 
mutant. In this study, the chlorophyll content of the double mutant was significantly higher than that in Col-0 (Fig. S2A).

Absence of tonoplast V-ATPase affects the long-distance transport of nitrogen between shoots and roots

Since the vha-a2vha-a3 double mutant accumulated more ammonium in shoots, the metabolism and long-distance transport of nitrogen between shoots and roots were investigated. The relative expression of NRT1.5 was down-regulated and that of NRT1.8 was up-regulated (Fig. 4A and B), which caused more nitrate to transport from shoots to roots in the vha-a2vha-a3 double mutant (Fig. 3A); moreover, NR activity was notably induced (Fig. 3B). However, we were surprised to find a significant decrease in ammonium content in roots of the vha-a2vha-a3 mutant (Fig. 3C), and there was no significant difference in GS activity between the two strains (Fig. 3D). To understand this in more detail, the relative expression of AMT2.1 and xylem sap $\mathrm{NH}_{4}{ }^{+}$content were measured in the double mutant. The relative expression of AMT2.1 was up-regulated two-fold, and xylem sap $\mathrm{NH}_{4}{ }^{+}$content was $66 \%$ higher than that of Col-0 (Fig. 4C and D). Similarly, the root/shoot ratio of $\mathrm{NH}_{4}{ }^{+}$decreased significantly in the vha-a2vha-a3 mutant, which caused more $\mathrm{NH}_{4}{ }^{+}$to be transported from roots to shoots, where it was accumulated, thereby aggravating poisoning by $\mathrm{NH}_{4}{ }^{+}$in the vha-a2vha-a3 double mutant plants (Fig. S2B, Fig. 3C).

Impaired tonoplast V-ATPase activity influenced ion homeostasis

Ion balance in cells is the basis for normal growth and development of plants, and the proton pumps located on the tonoplast play an important role in regulating ion homeostasis in cells $[14,15]$. Thus, we assessed whether ion imbalance was disrupted in plants when the tonoplast V-ATPase was absent. Cations in rosette leaves, including potassium $\left(\mathrm{K}^{+}\right)$, calcium $\left(\mathrm{Ca}^{2+}\right)$, magnesium $\left(\mathrm{Mg}^{2+}\right)$, sodium $\left(\mathrm{Na}^{+}\right)$, iron $\left(\mathrm{Fe}^{2+}\right)$, manganese $\left(\mathrm{Mn}^{2+}\right)$, copper $\left(\mathrm{Cu}^{2+}\right)$, and zinc $\left(\mathrm{Zn}^{2+}\right)$, were extracted from four-week-old plants and analyzed by ICP-MS (Fig. 5). The content of $\mathrm{Ca}^{2+}, \mathrm{Mg}^{2+}$, and $\mathrm{Na}^{+}$decreased and the content of $\mathrm{Fe}^{2+}$, $\mathrm{Mn}^{2+}$, and $\mathrm{Cu}^{2+}$ increased, indicating that the cation concentrations were disturbed in plants when $\mathrm{V}$ ATPase activity at the tonoplast was absent, which correlated to decreased plant growth and premature senescence.

Growth retardation was alleviated and senescence delayed when adding additional $\mathrm{K}^{+}$to the vha-a2vhaa3 double mutant

Reduced leaf growth of the vha-a2vha-a3 double mutant under the control conditions was accompanied by the etiolation of leaves; these symptoms were similar to those caused by calcium deficiency in the cax1cax3 double mutant that lacked two vacuolar $\mathrm{Ca}^{2+} / \mathrm{H}^{+}$antiporters $[32,33]$. To address the lower calcium content in the double mutant, additional doses of $\mathrm{Ca}^{2+}(0.5 \mathrm{mM}, 2.5 \mathrm{mM}, 5 \mathrm{mM})$ were supplied to the vha-a2vha-a3 double mutant during hydroponic growth for four weeks. It was observed that the yellowing phenotype of the mutant was not restored after addition of any of the three concentrations of $\mathrm{Ca}^{2+}$. Furthermore, plants were markedly smaller than wild-type (Fig. S3A). 
Potassium, as the most abundant cation in higher plants, plays a critical role in plant nutrition, growth, ion homeostasis, enzyme activities, and osmoregulation [23]. Therefore, different doses of $\mathrm{K}^{+}(2 \mathrm{mM}$, $4 \mathrm{mM}, 6 \mathrm{mM}, 8 \mathrm{mM}, 10 \mathrm{mM}, 15 \mathrm{mM}$, and $20 \mathrm{mM}$ ) were supplied to the plants. The difference in plant size between the vha-a2vha-a3 double mutant and the wild-type gradually diminished when increasing the external $\mathrm{K}^{+}$concentrations from $2 \mathrm{mM}$ to $10 \mathrm{mM}$, and the symptoms of leaf chlorosis were alleviated (Fig. $\mathrm{S} 3 \mathrm{~B})$. However, these effects were reduced when the concentration of $\mathrm{K}^{+}$in the culture solution was $15 \mathrm{mM}$ and $20 \mathrm{mM}$. Compared with $2 \mathrm{mM} \mathrm{K}^{+}$supplied, the changes in the WT were not significant after potassium addition. $\mathrm{NO}_{3}{ }^{-}, \mathrm{NH}_{4}{ }^{+}$, and chlorophyll content were also determined, and the data showed a downward trend when the potassium concentration range was $2 \mathrm{mM}$ to $10 \mathrm{mM}$, with a slight upward trend at $15 \mathrm{mM}$ and $20 \mathrm{mM}$ (Fig. S4A-C).

In this study, the vha-a2vha-a3 double mutant displayed increases in biomass of both shoots and roots when $10 \mathrm{mM}$ external $\mathrm{K}^{+}$was supplied (Fig. 6A). Biomass of mutant plants was increased by $74 \%$ and relative expression levels of SAG29 decreased by $87 \%$ with applied potassium concentrations from $2 \mathrm{mM}$ to $10 \mathrm{mM}$ (Fig. 6B and C). At the same time, the leaf area, total length, surface area, root volume, and number of root tips and forks were enhanced in WT and mutant plants when potassium concentration was $10 \mathrm{mM}$ (Fig. S5). The vha-a2vha-a3 double mutant plants especially showed a much stronger growth in increased potassium, indicating that exogenous potassium could alleviate the growth inhibition in these double mutant plants and delay senescence to some extent.

Nitrogen absorption was promoted, and ammonium accumulation reduced with additional $\mathrm{K}^{+}$supply to the mutant

It has been long noticed that $\mathrm{K}^{+} / \mathrm{NO}_{3}{ }^{-}$absorption and transport in vascular plants are somehow coordinated, playing a critical role in promoting nitrogen absorption [24-27]. Thus, TN accumulation and TN concentration were measured and found to have increased by $73 \%$ and $5 \%$, respectively, compared with $2 \mathrm{mM} \mathrm{K}^{+}$, which aid to improve the growth of the mutant plants (Fig. 7A and B). In contrast, the biomass and nitrogen absorption of Col-0 showed no significant difference between $2 \mathrm{mM}$ and $10 \mathrm{mM}$ supplied $\mathrm{K}^{+}$(Fig. 6B, 7A and B).

Previous studies have concluded that an increased $\mathrm{K}^{+}$supply or a restoration of $\mathrm{K}^{+}$transport can rapidly relieve $\mathrm{NH}_{4}{ }^{+}$toxicity $[28,29]$, but whether it could reduce endogenous ammonium toxicity remains unclear. Surprisingly, it was found that the ammonium and chlorophyll content were also reduced by $32 \%$ and $13 \%$, respectively, after adding $10 \mathrm{mM}$ potassium in the nutrient solution (Fig. 7C and D, Fig. S4B and C). Thus, the increase of nitrogen accumulation and the decrease of ammonium accumulation in shoots were beneficial to restore the growth performance and delay senescence when additional $\mathrm{K}^{+}$was supplied, but the specific reasons need to be further studied.

\section{Discussion}


The two proton pumps in plant vacuoles, vacuolar $\mathrm{H}^{+}$-ATPase (V-ATPase) and vacuolar $\mathrm{H}^{+}$-PPase (VPPase), are highly abundant tonoplast proteins and play important roles in plant growth and development. They energize the massive fluxes of ions and metabolites that are required for vacuolar function throughout the plant life cycle [4]. To investigate the role of V-ATPase in the growth and development of plants, we selected a loss-of-function A. thaliana mutant of V-ATPase in the tonoplast, the double mutant vha-a2vha-a3, which lacks the two tonoplast-localized isoforms of the membraneintegral V-ATPase subunit VHA-a.

The mutant plants are viable but show severe growth inhibition and premature aging, including reduced biomass and leaf area, reduced total length, surface area, root volume, and number of root tips and forks. Furthermore, the TN accumulation and TN content of the vha-a2vha-a3 double mutant were determined to be lower than those of the wild-type plants. Similarly, the expression of NRT1.1 was down-regulated in the double mutant, indicating that a lack of V-ATPase activity might inhibit the uptake of nitrate by plant roots, thus accelerating the early aging of plants.

Nitrate is the main source of nitrogen, and once taken up into the root, it is partitioned between a small active cytosolic metabolite pool and a large storage pool in the vacuole [30]. Nitrate accumulation in the vacuole is primarily mediated by the $\mathrm{NO}_{3}{ }^{-} / \mathrm{H}^{+}$exchanger AtCLCa and depends on the $\mathrm{pH}$ gradient [31]. Our data suggest that reduced V-ATPase activity could lead to higher nitrate levels in the cytosol, which in turn stimulate the activity of nitrate reductase. This notion was supported by previous studies in which the tonoplast V-ATPase-deficient mutant vha-a2vha-a3 contained $80 \%$ less nitrate, but also displayed an increase by $90 \%$ of NR activity [4]. Accordingly, the vha-a2vha-a3 double mutant accumulated $31 \%$ more ammonium in shoots than the wild-type, a condition that might be toxic to plants. It is obvious from the results obtained in this study that chlorophyll content of vha-a2vha-a3 double mutants was higher than that in wild-type. Our data revealed that the nitrate metabolism was blocked when V-ATPase activity was absent in the tonoplast; one possible scenario to explain this is that the vacuolar $\mathrm{pH}$ was increased in the vha-a2vha-a3 double mutant. Thus, vacuoles cannot retain optimal acidity and the intracellular environment conducive to the normal metabolism of nitrate in cells.

It is interesting that in Arabidopsis, lack of tonoplast V-ATPase activity could affect the long-distance transport of nitrogen between shoots and roots. Our results showed that the relative expression of NRT1.5 was down-regulated and that of NRT1.8 up-regulated in the mutant plants, which caused more nitrate to accumulate and induced a notable increase in NR activity in the roots of mutant plants. However, we were surprised to find a notable decrease in ammonium content in roots of mutant plants, but no difference in GS activity between WT and mutant. To explain the decrease in the accumulation of ammonium in the roots of the mutant, we considered AMT2.1, which encodes a high-affinity ammonium transporter responsible for the transport of ammonium from roots to shoots. We found that the relative expression of AMT2.1 was up-regulated in the mutant, and xylem sap $\mathrm{NH}_{4}{ }^{+}$content was about twice as high as that in WT, which caused more ammonium to be transported from roots to shoots. This in turn caused 
ammonium accumulation, aggravating the ammonium poisoning in shoots of vha-a2vha-a3 double mutant plants.

The activity of the proton pump in vacuole membranes can regulate the ion homeostasis in cells, which is necessary for normal growth and development of plants [14, 15]. Membrane-bound transport systems regulating cytosolic ion balance $\left(\mathrm{K}^{+}, \mathrm{Na}^{+}, \mathrm{Ca}^{2+}\right.$, and $\left.\mathrm{Fe}^{2+}\right)$ and ion accumulation in the vacuole can be considered of crucial importance for adaptation to stress conditions [16]. To corroborate the fact that lack of tonoplast V-ATPase activity leads to ion disorder, the $\mathrm{Ca}^{2+}, \mathrm{Mg}^{2+}$, and $\mathrm{Na}^{+}$contents were decreased and the content of $\mathrm{Fe}^{2+}, \mathrm{Mn}^{2+}$, and $\mathrm{Cu}^{2+}$ increased. Vacuolar membrane proton pumps, as the power sources of substance exchange in the barrier between cytoplasm and vacuoles, play an important role in separating harmful ions from vacuoles, thus reducing excessive ions' toxicity to cells [34]. There are various metal ion transporters on the vacuolar membrane, which transport metal ions, depending on the energy produced by the activity of the vacuolar membrane proton pumps and $\mathrm{H}^{+}$gradient [35]. The disturbance of ions in cells may be due to the decrease of the electrochemical potential gradient between the vacuole membrane and cytoplasm, which leads to the alkalization of vacuoles, thereby affecting the activity of various ion transporters and channel proteins in vacuole membranes.

Reduced leaf growth of the vha-a2vha-a3 double mutant under normal growth conditions was accompanied by less leaf area and etiolated leaves. These are similar to symptoms of calcium deficiency also found in the cax1 cax3 double mutant that lacks two vacuolar $\mathrm{Ca}^{2+} / \mathrm{H}^{+}$antiporters [32, 33]. At the same time, our results showed that the calcium content in the mutants was reduced. Therefore, was the inhibition of mutant growth caused by calcium deficiency? To answer this question, we supplemented the hydroponic nutrient solution with different concentrations of calcium; the growth inhibition of mutants did not abate, indicating that calcium deficiency was not the main factor inhibiting plant growth. Taking into consideration that nitrate is one of the most abundant anions in plants, whose absorption and transport are believed to be accompanied by $\mathrm{K}^{+}[26,27]$, we supplied different $\mathrm{K}^{+}$doses to the double mutant. The growth inhibition of mutants was alleviated to some extent by potassium supplementation; this included increased biomass and leaf area, enhanced total length, surface area, root volume, and number of root tips and forks. However, the effect was reduced when the concentration of $\mathrm{K}^{+}$in the culture solution was $15 \mathrm{mM}$ and $20 \mathrm{mM}$. This indicated that the mutants are not potassium-deficient and that the V-ATPases may play a different role in the cell, such as acting as activators of certain $\mathrm{K}^{+}$dependent enzymes, thereby promoting plant growth. In addition, the acquisition rates of $\mathrm{K}^{+}$and $\mathrm{NO}_{3}{ }^{-}$are often positively correlated and enhance each other [26, 27]; potassium supplementation increased TN accumulation, and ammonium accumulation was also reduced, delaying cell senescence and death. These data demonstrate that the potassium supplementation has a positive effect on alleviating the growth inhibition phenotype of mutants. One possible explain this is that potassium and nitrogen interact in beneficial ways to aid in the absorption of nitrogen by plants, leading to increased biomass of mutants. Conversely, potassium may alleviate ammonium toxicity in mutants; this notion is supported by 
previous work showing that an increased $\mathrm{K}^{+}$supply or a restoration of $\mathrm{K}^{+}$transport can rapidly alleviate $\mathrm{NH}_{4}{ }^{+}$toxicity $[28,29]$.

\section{Conclusions}

Taken together, we revealed that the V-ATPase double mutant plants can remain viable without VHA-a2 and VHA-a3. We elucidated the effects of tonoplast V-ATPase deficiencies on plant growth from different perspectives and demonstrated that potassium supplementation could effectively alleviate the growth inhibition phenotype of mutants, providing a new area for the study of the relationship between vacuolar $\mathrm{H}^{+}$-ATPase and potassium.

\section{Methods}

Plant materials and growth conditions

The Arabidopsis thaliana wild-type Columbia-0 (Col-0) was used as a control for the tonoplast V-ATPase double mutant (vha-a2vha-a3). The vha-a2vha-a3 double mutant identified in the $F_{2}$ derived from a cross of homozygous vha-a2 (SALK_142642) and vha-a3 (SALK_29786) individuals by the Krebs' laboratory (Heidelberg Institute for Plant Science, University of Heidelberg, Germany). And the vha-a2vha-a3 double mutant was kindly provided to us by Krebs [4]. The experiments were carried out in a phytotron (MGC800HP-2, Blue Pard Test Equipment Company, Shanghai, China) at the Hunan Agricultural University, Changsha, China. The phytotron was set at $16 \mathrm{~h}$ light/ $8 \mathrm{~h}$ dark period, $70 \%$ relative humidity and a constant temperature of $22{ }^{\circ} \mathrm{C}$. Seeds were sown in a matrix consisting of vermiculite and perlite at a ratio of 3:2, and allowed to germinate and grow for $10 d[36,37]$. Subsequently, the seedlings with a pair of young leaves were transferred and grown hydroponically in $600 \mathrm{~mL}$ plastic pots with a black film on the outside, as described by Gong et al [38]. Nine plants were grown in each plastic pot. These pots were arranged in a completely randomized design with three biological replicates. To eliminate edge effects, the positions of the pots were interchanged when refreshing the media. The nutrient solution $(\mathrm{pH}=5.8)$ provided to plants was replaced every five days, as described in Han et al [39]. The nutrient solution used for both species consisted of $1.25 \mathrm{mM} \mathrm{KNO}_{3}, 0.625 \mathrm{mM} \mathrm{KH}_{2} \mathrm{PO}_{4}, 0.5 \mathrm{mM} \mathrm{Ca}\left(\mathrm{NO}_{3}\right)_{2} \cdot 4 \mathrm{H}_{2} \mathrm{O}, 0.5 \mathrm{mM}$ $\mathrm{MgSO}_{4}, 0.025 \mathrm{mM} \mathrm{Fe}$-EDTA and $0.25 \mathrm{mM}$ micronutrients (stock solution concentrations: $70 \mathrm{mM} \mathrm{H}_{3} \mathrm{BO}_{3}$, $14 \mathrm{mM} \mathrm{MnCl}_{2}, 1 \mathrm{mM} \mathrm{ZnSO}_{4}, 0.5 \mathrm{mM} \mathrm{CuSO}_{4}$, and $\left.0.2 \mathrm{mM} \mathrm{Na}_{2} \mathrm{MoO}_{4}\right)$.

When treated with potassium, the seedlings were transplanted and grown in the nutrient solution mentioned above for $30 \mathrm{~d}$ under different growth conditions, except for the concentration of potassium supplied ( $2 \mathrm{mM}, 4 \mathrm{mM}, 6 \mathrm{mM}, 8 \mathrm{mM}, 10 \mathrm{mM}, 15 \mathrm{mM}$, and $20 \mathrm{mM})$. In addition to changing the concentration of calcium ( $2.5 \mathrm{mM}$ and $5 \mathrm{mM})$ in the nutrient solution, the other growth conditions were as described above when calcium was added.

Measurement of leaf rosette areas 
The rosette leaves were collected from A. thaliana seedlings grown for four weeks, after which their area was measured using a leaf area meter (Cl-202 LASER AREA METER, U.S.A.).

Measurement of root configuration

The roots were sampled from A. thaliana seedlings grown for four weeks; they were spread fully in a $1,000 \mathrm{~cm}^{3}(25 \mathrm{~cm} \times 20 \mathrm{~cm} \times 2 \mathrm{~cm})$ transparent plastic container filled with distilled water. After the impurities on the root surface were washed away, the root analysis and measurement software WinRHIZO (EPSON Expression 11000XL, Japan) was used to determine root configuration indices, including the total root length, root surface area, root volume, and number of root tips and forks.

Determination of nitrogen concentration

Whole seedlings of $A$. thaliana grown hydroponically for four weeks were sampled and oven-dried at $105^{\circ} \mathrm{C}$ for $30 \mathrm{~min}$, followed by $65^{\circ} \mathrm{C}$ to a constant weight. The samples were digested with $\mathrm{H}_{2} \mathrm{SO}_{4}-\mathrm{H}_{2} \mathrm{O}_{2}$ $\left(5 \mathrm{~mL} \mathrm{H}_{2} \mathrm{SO}_{4}\right.$ ) at $350{ }^{\circ} \mathrm{C}$ and were determined using an AA3 continuous-flow auto-analyzer [39]. The following formula was used: Total $\mathrm{N}=[\mathrm{N}] \times$ biomass.

Assays of $\mathrm{NO}_{3}{ }^{-}$concentration

The fresh plants were divided into shoots and roots as described by Han et al [39], and nitrate was extracted from tissue samples (shoot: $1 \mathrm{~g}$; root: $0.5 \mathrm{~g}$ ). The samples were soaked in deionized water and bathed in a boiling water bath for $30 \mathrm{~min}$. Then $0.1 \mathrm{~mL}$ of the sample solution was taken, $0.4 \mathrm{~mL}$ of $5 \%$ salicylic acid- $\mathrm{H}_{2} \mathrm{SO}_{4}$ solution ( $5 \mathrm{~g}$ salicylic acid dissolved in $100 \mathrm{~mL} \mathrm{H}_{2} \mathrm{SO}_{4}$ ) was added, mixed well and allowed to react at room temperature for $20 \mathrm{~min}$. Subsequently, $9.5 \mathrm{~mL}$ of $8 \%$ sodium hydroxide solution was added to the mixture and allowed to cool to room temperature. The $\mathrm{NO}_{3}{ }^{-}$concentration was measured spectrophotometrically at $410 \mathrm{~nm}$ following the method of Cataldo et al [40].

Measurement of $\mathrm{NH}_{4}{ }^{+}$concentration

To determine the concentration of $\mathrm{NH}_{4}{ }^{+}$, shoots and roots were sampled as described above and extracted with deionized water for $30 \mathrm{~min} . \mathrm{NH}_{4}{ }^{+}$concentration was measured using indophenol blue colorimetry at $630 \mathrm{~nm}$ [41].

Determination of the activities of nitrate reductase (NR) and glutamine synthetase (GS)

The method for determining NR activity was slightly modified on the basis of previous studies $[42,43]$. The fresh plants were divided into shoots and roots and then frozen. A small amount of quartz sand and $5 \mathrm{~mL}$ phosphate buffer $(0.1 \mathrm{M}, \mathrm{pH}=7.5)$ were added to a pre-frozen mortar, and the frozen samples were ground to homogeneity using a chilled pestle. The homogenates were centrifuged at $2,000 \mathrm{xg}$ for $15 \mathrm{~min}$ at $4{ }^{\circ} \mathrm{C}$. The supernatant fluid was used to determine the activity of NADH-dependent NR. The reaction mixture consisted of $0.4 \mathrm{~mL}$ supernatant, $0.1 \mathrm{M} \mathrm{KNO}_{3}$, and $3 \mathrm{mM} \mathrm{NADH}$. The reaction was terminated 
after 30 min at $25^{\circ} \mathrm{C}$ by adding $1 \%$ sulfanilamide and a-naphthylamine. The amount of reaction product was measured at $540 \mathrm{~nm}$ using a UV-2600 spectrophotometer (Shimadzu Corp., Kyoto, Japan).

The frozen plant samples were ground to homogeneity as presented above with $3 \mathrm{~mL} 50 \mathrm{mM}$ Tris- $\mathrm{HCl}$ buffer ( $\mathrm{pH}=8.0)$, containing $2 \mathrm{mM} \mathrm{DTT}, 2 \mathrm{mM} \mathrm{Mg}^{2+}$ and $0.4 \mathrm{M}$ sucrose. The homogenate was centrifuged at $10,000 \times \mathrm{g}$ for $10 \mathrm{~min}$ at $4{ }^{\circ} \mathrm{C}$. The supernatant was examined for the GS activity according to the method described by Zhang et al [44].

Chlorophyll concentration assays

Fresh rosette leaves $(0.2 \mathrm{~g})$ were sampled and extracted in $10 \mathrm{~mL}$ absolute ethanol:acetone (1:1) for $48 \mathrm{~h}$ in the dark at $4{ }^{\circ} \mathrm{C}$ [45]. The absorbance of the extract was measured at 663 and $645 \mathrm{~nm}$ using a UV-VIS spectrophotometer (UV-2600, Shimadzu, Japan) to estimate total chlorophyll concentrations.

RNA extraction and qRT-PCR assay

The seedlings were grown under normal conditions for $30 \mathrm{~d}$ after which shoots $(100 \mathrm{mg})$ and roots (100 mg) were harvested for RNA analysis. Total RNA was extracted with $1 \mathrm{~mL}$ TRIzol reagent (Invitrogen, USA), precipitated with an equal volume of isopropanol, washed with $75 \%$ ethanol, and dissolved in RNAase-free water. The first-strand cDNA was synthesized from total RNA using PrimeScript reverse transcription (RT) reagent kit (TaKaRa, Shiga, Japan) in accordance with the manufacturer's protocol. The relative expression of genes was determined by the SYBR Green RT-PCR kit (TaKaRa) with a pair of genespecific primers. The RT-PCR analysis was performed with the StepOnePlus ${ }^{\text {TM }}$ Real-Time PCR Instrument (StepOnePlus ${ }^{\text {TM }}$, Life Technologies Hildings Pte Ltd, Singapore) and the reaction volume and the thermal cycling conditions followed the protocol of the manufacturer. The thermal cycles were as follows: $95^{\circ} \mathrm{C}$ for $3 \mathrm{~min}$, followed by 40 cycles of $95^{\circ} \mathrm{C}$ for $10 \mathrm{~s}$, then $60^{\circ} \mathrm{C}$ for $30 \mathrm{~s}$. A melt curve analysis was performed to ensure the primer gene specificity, as follows: $95^{\circ} \mathrm{C}$ for $15 \mathrm{~s}, 60^{\circ} \mathrm{C}$ for $1 \mathrm{~min}, 60-95^{\circ} \mathrm{C}$ for $15 \mathrm{~s}$. The primers used in this analysis are presented in Supplementary Table 1, and the expression data were normalized to Actin $[46,47]$.

Determination of ammonium in xylem sap

Seedlings were gathered and stripped of leaves, and the stems were cut at about $1 \mathrm{~cm}$ from the root and shielded from light. The xylem sap was collected with capillaries within $2 \mathrm{~h}$ of cutting. Each plant was covered with one capillary for xylem sap collection. Three biological replicates were conducted for each kind of plant. The xylem sap was collected from 20 plants and the total volume was approximately $50 \mu \mathrm{L}$ for each replicate [48]. Ammonium was determined as described by Santoni et al [41].

Determination of cation content

The method for determining cationic content was slightly modified from a previous study [49]. The seedlings were hydroponically grown for four weeks and the shoots oven-dried at $105^{\circ} \mathrm{C}$ for $30 \mathrm{~min}$, followed by $65^{\circ} \mathrm{C}$ to constant weight, and then ground into a fine powder. Following this, $5 \mathrm{~mL} \mathrm{HNO}_{3}$ was 
added to about $100 \mathrm{mg}$ samples and bathed in boiling water for $2 \mathrm{~h}$. Then the extracting solution was complemented with deionized water to $50 \mathrm{~mL}$ after cooling. The cation content was measured by inductively coupled plasma-mass spectrometry (ICP-MS, ELAN DRC-e, Perkin Elmer, Shelton, USA).

\section{Statistics}

Statistical Package for the Social Sciences 17.0 (SPSS, Chicago, IL, USA) was used for one-way analysis of variance (ANOVA) and Tukey's honestly significant difference (HSD) multiple comparison tests of data. The experiments were arranged in a completely randomized design with three biological replicates. Different letters above columns in the figures indicate statistical differences $(p \leq 0.05)$ between the wildtype and vha-a2vha-a3 double mutant and/or between different treatments.

Accession numbers

Sequence data for this article were obtained from the GenBank/EMBL data libraries under accession numbers Actin2 (AT3G18780), AMT2.1 (AT2G38290), NRT1.5 (AT1G32450), NRT1.8 (AT4G21680), and SAG29 (AT5G13170).

\section{Declarations}

Ethics approval and consent to participate

Not applicable.

Consent for publication

Not applicable.

Availability of data and material

The datasets used and/or analyzed during the current study are available from the corresponding author on reasonable request.

Competing interests 
The authors declare that the research was conducted in the absence of any commercial or financial relationships that could be construed as a potential conflict of interest.

Funding

This study was financially supported in part by the National Key R\&D Program of China (2017YFD0200100 and 2017YFD0200103), the Hunan Provincial Recruitment Program of Foreign Experts, the National Oilseed Rape Production Technology System of China, "2011 Plan” supported by The Chinese Ministry of Education, and the Double FirstClass Construction Project of Hunan Agricultural University (kxk201801005).

Authors' contributions

GHL and ZHZ designed the experiments; GHL performed the experiments; GHL and ZHZ analyzed the data and wrote the manuscripts. HXS and ZHZ edited manuscript. All authors read and approved the final manuscript.

Acknowledgments

We thank Dr. Ji-Ming Gong, Shanghai Institute of Plant Physiology and Ecology, Shanghai Institutes for Biological Sciences, for providing $A$. thaliana (Col-0) material; Dr. Melanie Krebs, Heidelberg Institute for Plant Sciences, University of Heidelberg, Germany, for providing the $A$. thaliana mutant line vha-a2vha-a3.

\section{Abbreviations}

WT

wild-type

V-ATPase

vacuolar $\mathrm{H}^{+}$-ATPase

V-PPase

vacuolar $\mathrm{H}^{+}$-pyrophosphatase

TN

total nitrogen 
nitrogen

NR

nitrate reductase

GS

glutamine synthetase

$\mathrm{NO}_{3}{ }^{-}$

nitrate

$\mathrm{NH}_{4}^{+}$

ammonium

TGN/EE

trans-Golgi network/early endosome

CLC

chloride channel

qRT-PCR

quantitative real-time PCR

ICP-MS

inductively coupled plasma-mass spectrometry

ANOVA

one-way analysis of variance

SPSS

statistical package for the social sciences

HSD

honestly significant difference

SAG

senescence-associated gene

AMT

ammonium transporter

NRT

nitrate transporter

$\mathrm{R} / \mathrm{S}$

root/shoot ratio

\section{References}

1.

Kriegel A, Andrés Z, Medzihradszky A, Krüger F, Scholl S, Delang S, et al. Job sharing in the endomembrane system: vacuolar acidification requires the combined activity of V-ATPase and V-PPase. Plant Cell. 2015;27:3383-96.

2. 
Liao XR, Chen T, Liu XL. The formation and function of plant vacuole. Chin J Cell Biol. 2002;24:95-101. 3.

Shen QR, Tang L, Xu YC. A review on the behavior of nitrate in vacuoles of plants. Acta Pedol Sin. 2003;40:465-70.

4.

Krebs M, Beyhl D, Görlich E, Al-Rasheid KA, Marten I, Stierhof YD, et al. Arabidopsis V-ATPase activity at the tonoplast is required for efficient nutrient storage but not for sodium accumulation. Proc Natl Acad Sci USA. 2010;107:3251-6.

5 .

Hedrich R, Kurkdjian A, Guern J, Flugge Ul. Comparative studies on the electrical properties of the $\mathrm{H}^{+}$ translocating ATPase and pyrophosphatase of the vacuolar-lysosomal compartment. EMBO J. 1989;8:2835-41.

6.

Gaxiola RA, Palmgren MG, Schumacher K. Plant proton pumps. FEBS Lett. 2007;581:2204-14.

7.

Neuhaus HE, Trentmann O. Regulation of transport processes across the tonoplast. Front Plant Sci. $2014 ; 5: 460$.

8.

Carter C, Pan S, Zouhar J, Avila EL, Girke T, Raikhel NV. The vegetative vacuole proteome of Arabidopsis thaliana reveals predicted and unexpected proteins. Plant Cell. 2004;16:3285-303.

9.

Jaquinod M, Villiers F, Kieffer-Jaquinod S, Hugouvieux V, Bruley C, Garin J, et al. A proteomics dissection of Arabidopsis thaliana vacuoles isolated from cell culture. Mol Cell Proteomics. 2007;6:394-412. 10.

Cipriano DJ, Wang Y, Bond S, Hinton A, Jefferies KC, Qi J, et al. Structure and regulation of the vacuolar ATPase. Biochim Biophys Acta. 2008;1777:599-604.

11.

Luo YS. Research progress of $\mathrm{H}^{+}$-ATPase activities in plant plasma membrane and vacuolar membrane under salt stress. J Anhui Agric Sci. 2012;40:263. -1265,1280..

12.

Dettmer J, Hong-Hermesdorf A, Stierhof YD, Schumacher K. Vacuolar $\mathrm{H}^{+}$-ATPase activity is required for endocytic and secretory trafficking in Arabidopsis. Plant Cell. 2006;18:715-30.

13.

Liao Q, Jian SF, Song HX, Guan CY, Lepo JE, Ismail AM, et al. Balance between nitrogen use efficiency and cadmium tolerance in Brassica napus and Arabidopsis thaliana. Plant Sci. 2019;284:57-66. 14.

Sun J, Chen SL, Dai SX, Wang RG, Li NY, Shen X. et al. Ion flux profiles and plant ion homeostasis control under salt stress. Plant Signal Behav. 2009;4:261-264.

15. 
Sze $\mathrm{H}$, Chanroj S. Plant endomembrane dynamics: studies of $\mathrm{K}^{+} / \mathrm{H}^{+}$antiporters provide insights on the effects of pH and ion homeostasis. Plant Physiol. 2018;177:875-895.

16.

Serrano R, Mulet JM, Rios G, Marquerz JA, de Larrinoa IF, Leube MP, et al. A glimpse of the mechanisms of ion homeostasis during salt stress. J Exp Bot. 1999;50:1023-36.

17.

Li H, Yu M, Du XQ, Wang ZF, Wu WH, Quintero FJ, et al. NRT1.5/NPF7.3 functions as a proton-coupled $\mathrm{H}^{+} / \mathrm{K}^{+}$antiporter for $\mathrm{K}^{+}$loading into the xylem in Arabidopsis. Plant Cell. 2017;29:2016-26.

18.

Wang Y, Wu WH. Potassium transport and signaling in higher plants. Annu Rev Plant Biol. 2013;64:45176.

19.

Véry AA, Nieves-Cordones M, Daly M, Khan I, Fizames C, Sentenac $\mathrm{H}$. Molecular biology of $\mathrm{K}^{+}$transport across the plant cell membrane: what do we learn from comparison between plant species? J Plant Physiol. 2014;171:748-69.

20.

Niu X, Bressan RA, Hasegawa PM, Pardo JM. Ion homeostasis in NaCl stress environment. Plant Physiol. 1995;109:735-42.

21.

Schachtman DP. Molecular insights into the structure and function of plant $\mathrm{K}^{+}$transport mechanisms. Biochim Biophys Acta. 2000;1465:127-39.

22.

Zhu JK, Liu J, Xiong L. Genetic analysis of salt tolerance in Arabidopsis: Evidence for a critical role of potassium nutrition. Plant Cell. 1998;10:1181-91.

23.

Wang B, Lüttge U, Ratajczak R. Effects of salt treatment and osmotic stress on V-ATPase and V-PPase in leaves of the halophyte Suaeda salsa. J Exp Bot. 2001;52:2355-65.

24.

Blevins DG, Barnett NM, Frost WB. Role of potassium and malate in nitrate uptake and translocation by wheat seedlings. Plant Physiol. 1978;62:784-8.

25.

Triplett EW, Barnett NM, Blevins DG. Organic acids and ionic balance in xylem exudate of wheat during nitrate or sulfate absorption. Plant Physiol. 1980;65:610-3.

26.

Coskun D, Britto DT, Li M, Oh S, Kronzucker HJ. Capacity and plasticity of potassium channels and highaffinity transporters in roots of barley and Arabidopsis. Plant Physiol. 2013;162:496-511.

27.

Xia XD, Fan XR, Wei J, Feng H, Qu HY, Xie D, et al. Rice nitrate transporter OsNPF2.4 functions in lowaffinity acquisition and long-distance transport. J Exp Bot. 2015;66:317-331.

28. 
Szczerba MW, Britto DT, Shabana AA, Balkos KD, Kronzucker HJ. $\mathrm{NH}_{4}{ }^{+}$stimulated and inhibited components of $\mathrm{K}^{+}$transport in rice (Oryza sativa L.). J Exp Bot. 2008;59:3415-23.

29.

ten Hoopen F, Cuin TA, Pedas P, Hegelund JN, Shabala S, Schjoerring JK, et al. Competition between uptake of ammonium and potassium in barley and Arabidopsis roots: molecular mechanisms and physiological consequences. J Exp Bot. 2010;61:2303-15.

30 .

Miller AJ, Fan X, Orsel M, Smith SJ, Well DM. Nitrate transport and signaling. J Exp Bot. 2007;58:2297306.

31.

De Angeli A, Monachello D, Ephritikhine G, Frachisse JM, Thomine S, Gambale F, et al. The nitrate/proton antiporter AtCLCa mediates nitrate accumulation in plant vacuoles. Nature. 2006;442:939-42.

32.

Cheng NH, Pittman JK, Barkla BJ, Shigaki T, Hirschi KD. The Arabidopsis cax1 mutant exhibits impaired ion homeostasis, development, and hormonal responses and reveals interplay among vacuolar transporters. Plant Cell. 2003;15:347-64.

33.

Cheng NH, Pittman JK, Shigaki T, Lachmansingh J, LeClere S, Lahner B, et al. Functional association of Arabidopsis CAX1 and CAX3 is required for normal growth and ion homeostasis. Plant Physiol. 2005;138:2048-60.

34.

Apse MP, Aharon GS, Snedden WA, Blumwald E. Salt tolerance conferred by overexpression of a vacuolar $\mathrm{Na}^{+} / \mathrm{H}^{+}$antiport in Arabidopsis. Science. 1999;285:1256-8.

35 .

Martinoia E. Vacuolar transporters-companions on a longtime journey. Plant Physiol. 2018;176:1384407.

36.

Jian S, Liao Q, Song H, Liu Q, Lepo JE, Guan C, et al. NRT1.1-related $\mathrm{NH}_{4}{ }^{+}$toxicity is associated with a disturbed balance between $\mathrm{NH}_{4}{ }^{+}$uptake and assimilation. Plant Physiol. 2018;178:1473-88.

37.

Liao Q, Zhou T, Yao JY, Han QF, Song HX, Guan CY, et al. Genome-scale characterization of the vacuole nitrate transporter Chloride Channel (CLC) genes and their transcriptional responses to diverse nutrient stresses in allotetraploid rapeseed. PLoS One. 2018. doi:10.1371/journal.pone.0208648. 38.

Gong JM, Lee DA, Schroeder JI. Long-distance root-to-shoot transport of phytochelatins and cadmium in Arabidopsis. Proc Natl Acad Sci USA. 2003;100:10118-23.

39.

Han YL, Song HX, Liao Q, Yu Y, Jian SF, Lepo JE, et al. Nitrogen use efficiency is mediated by vacuolar nitrate sequestration capacity in roots of Brassica napus. Plant Physiol. 2016;170:1684-1698. 
40.

Cataldo DA, Maroon M, Schrader LE, Youngs VL. Rapid colorimetric determination of nitrate in plant tissue by nitration of salicylic acid. Commun. Soil Sci Plant Anal.1975;6:71-80.

41.

Santoni S, Bonifacio E, Zanini E. Indophenol blue colorimetric method for measuring cation exchange capacity in sandy soils. Commun Soil Sci Plant Anal. 2001;32:2519-2530.

42.

Fan X, Jia L, Li Y, Smith SJ, Miller AJ, Shen Q. Comparing nitrate storage and remobilization in two rice cultivars that differ in their nitrogen use efficiency. J Exp Bot. 2007;58:1729-1740. 43.

Huang CB, Wang ZH, Wang XY, Li SX. Nitrate accumulation and reduction in Spinach and their relations to plant growth. J Agro Environ Sci. 2011;30:613-618.

44.

Zhang CF, Peng SB, Peng XX, Chavez AQ, Bennett J. Response of glutamine synthetase isoforms to nitrogen sources in rice (Oryza sativa L.) roots. Plant Sci. 1997;125:163-170.

45.

Wellburn AR, Lichtenthaler HK. Formulae and program to determine total carotenoids and chlorophylls a and b of leaf extracts in different solvents. Adv Photosyn Res. 1984;2:9-12. 46.

Bustin SA, Benes V, Garson JA, Hellemans J, Huggett J, Kubista M, et al. The MIQE guidelines: minimum information for publication of quantitative real-time PCR experiments. Clin Chem. 2009;55:611-622. 47.

Wang Z, Chen Y, Fang H, Shi H, Chen K, Zhang Z, et al. Selection of reference genes for quantitative reverse-transcription polymerase chain reaction normalization in Brassica napus under various stress conditions. Mol Genet Genomics. 2014;289:1023-1035.

48.

Han M, Wu W, Wu WH, Wang Y. Potassium transporter KUP7 is involved in $\mathrm{K}^{+}$acquisition and translocation in Arabidopsis root under $\mathrm{K}^{+}$-limited conditions. Mol Plant. 2016;9:437-446. 49.

Huang J, Zhang Y, Peng JS, Zhong C, Yi HY, Ow DW, et al. Fission yeast HMT1 lowers seed cadmium through phytochelatin-dependent vacuolar sequestration in Arabidopsis. Plant Physiol. 2012;158:17791788.

\section{Figures}




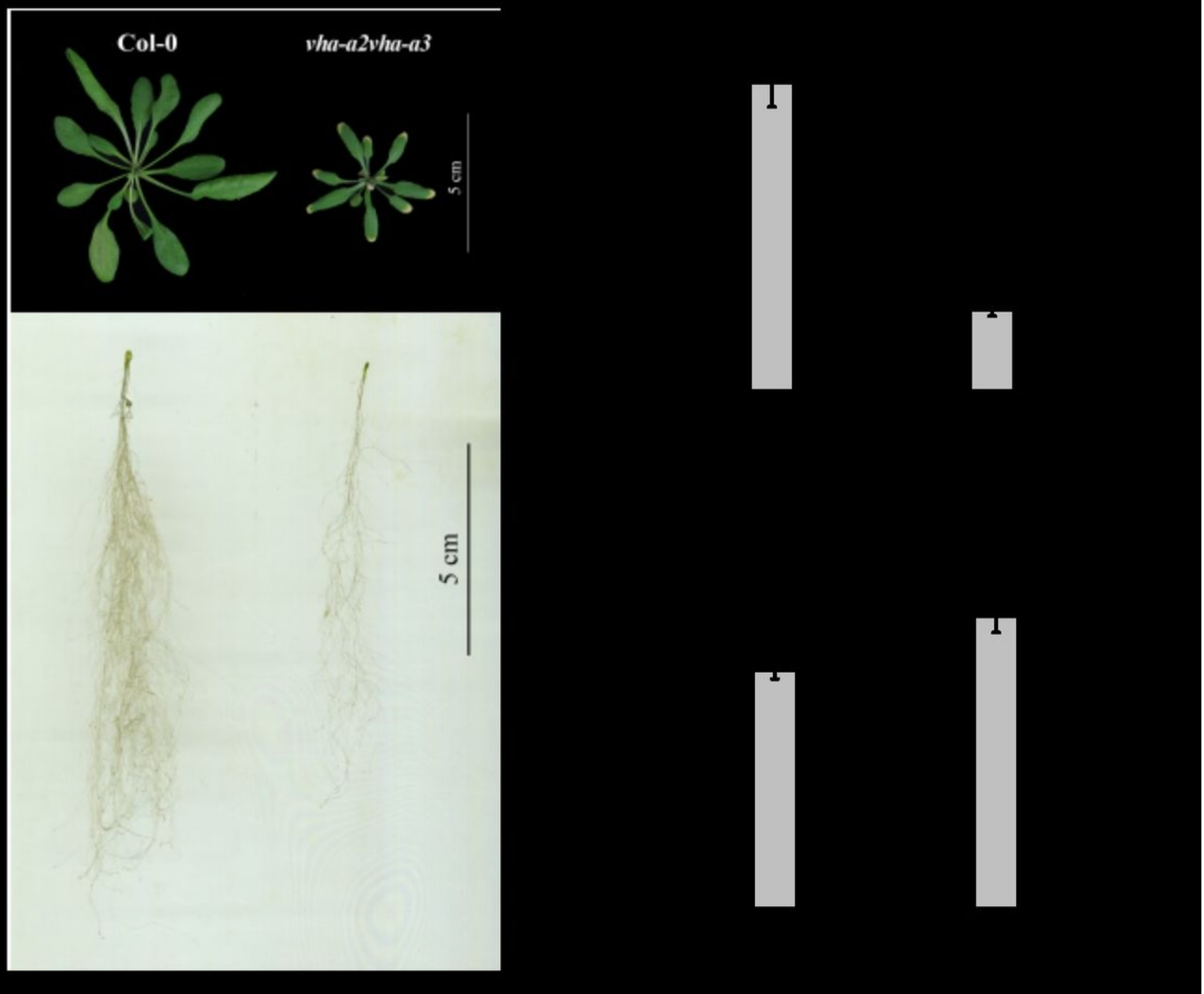

\section{Figure 1}

Loss of tonoplast V-ATPase causes severe growth inhibition and senescence. (A) Phenotype comparison between wild-type Arabidopsis (Col-0) and the vha-a2vha-a3 double mutant. (B) The biomass of Col-0 and vha-a2vha-a3 was determined. (C) Gene expression level of SAG29 in wild-type and vha-a2vha-a3 four-week-old leaves. Wild-type was set to $100 \%$ and error bars were defined as S.E. of $n=3$ biological replicates. Pictures show four-week-old plants in hydroponics. Error bars in (B) indicate S.D. of $n=3$ technical replicates. Asterisks $\left({ }^{*}\right)$ and $(* *)$ indicate significant differences at $p<0.05$ and $p<0.01$, respectively. 

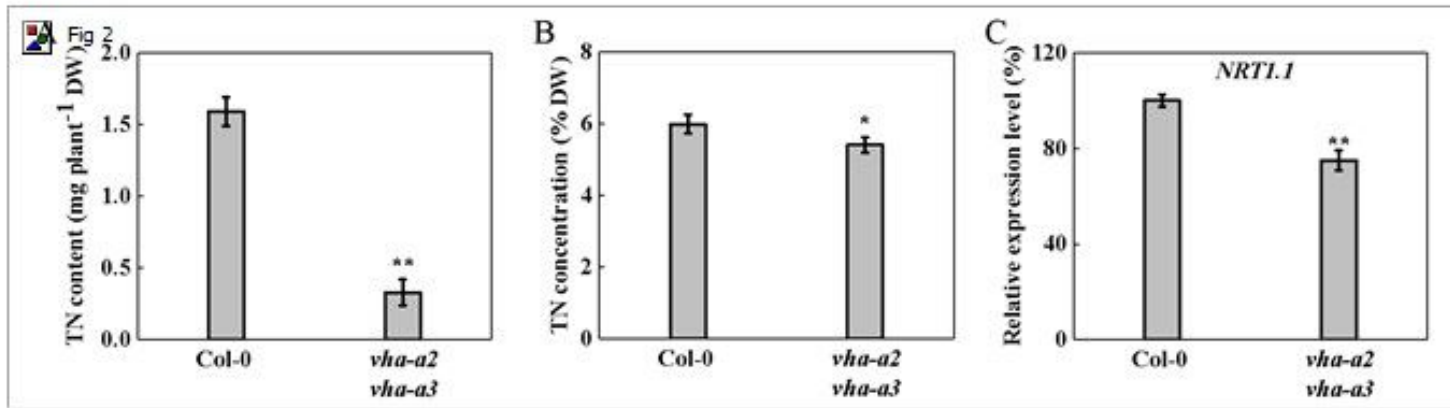

\section{Figure 2}

Nitrogen absorption in wild-type and the vha-a2vha-a3 double mutant. TN accumulation (A) and TN concentration (B) were measured of wild-type and vha-a2vha-a3 mutant. Data in (A) and (B) were mean \pm S.D. $(n=3)$. (C) Relative expression level of NRT1.1 in Col-0 and vha-a2vha-a3 was measured and Col-0 was set to $100 \%$. Data in are mean \pm S.E. $(n=3)$. Asterisks $\left({ }^{*}\right)$ and $\left({ }^{* *}\right)$ indicate significant differences at $p<0.05$ and $p<0.01$, respectively. DW, Dry weight. 


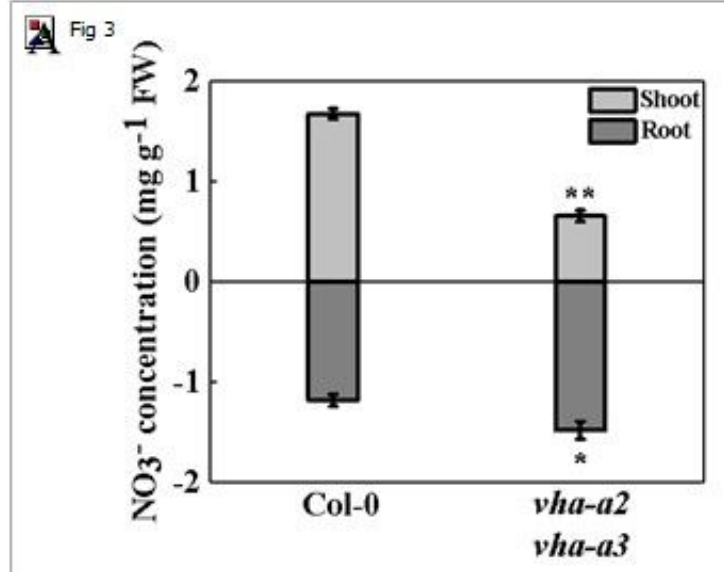

B

$\mathrm{C}$
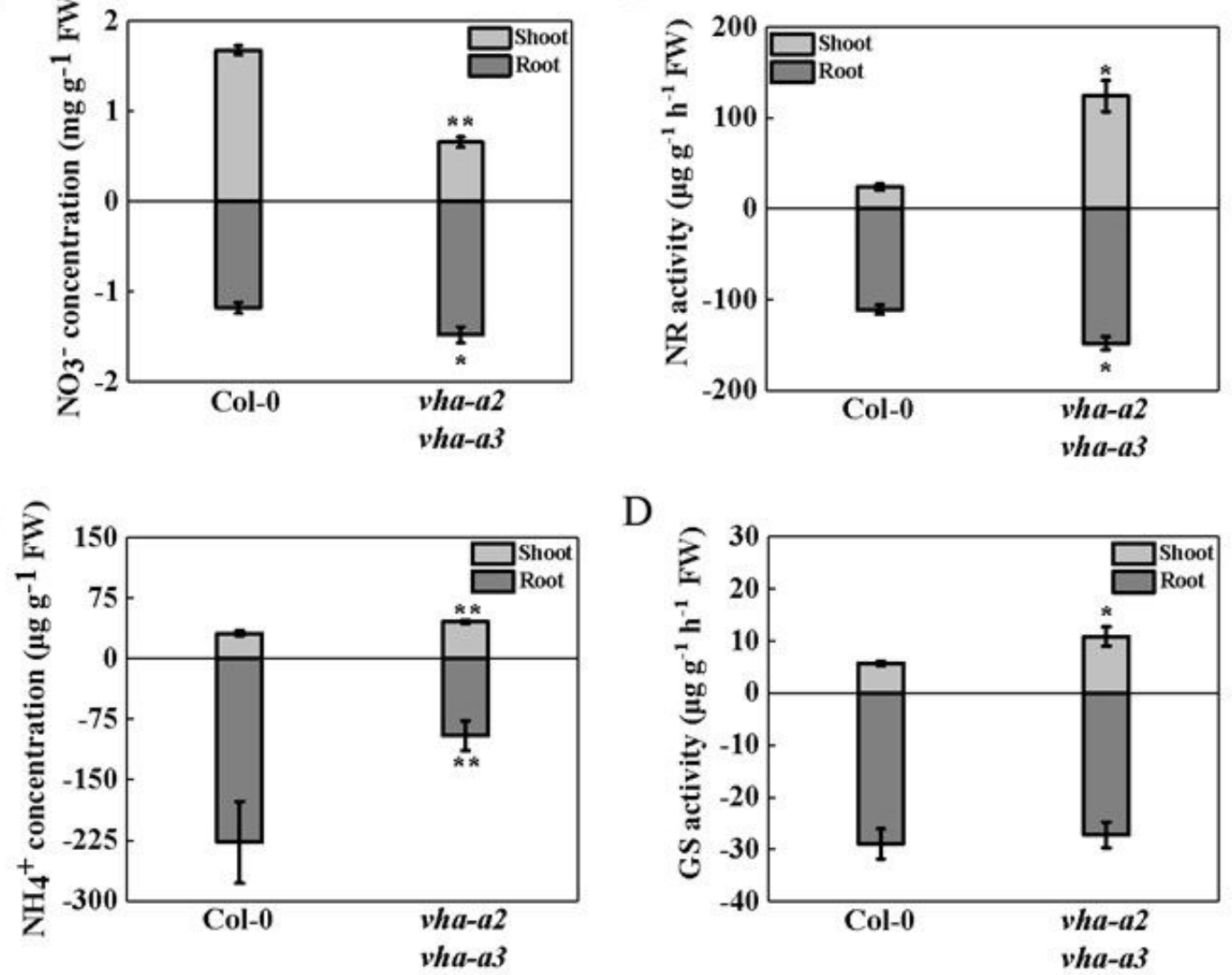

D

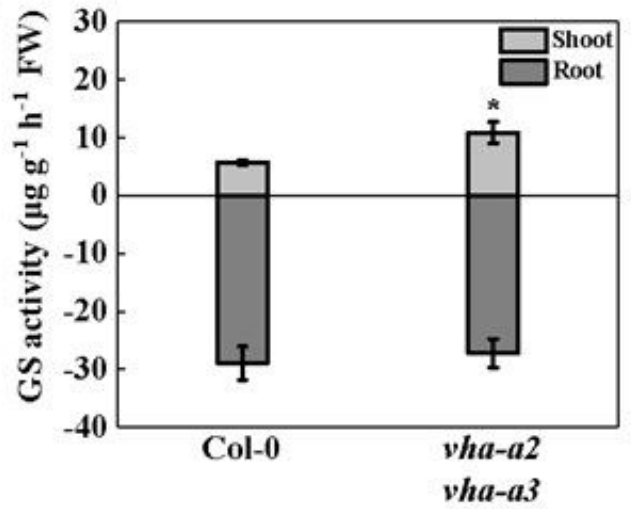

\section{Figure 3}

Nitrogen metabolism was measured using wild-type and vha-a2vha-a3 mutant four-week-old seedlings in hydroponics. NO3- concentration (A), NR activity (B), NH4+ concentration (C) and GS activity (D) of Col-0 and vha-a2vha-a3 mutant were determined in both shoots and roots. Error bars represent S.D. of three biological replicates. Asterisks $\left(^{*}\right)$ and $(* *)$ indicate significant differences at $p<0.05$ and $p<0.01$, respectively. FW, Fresh weight. 

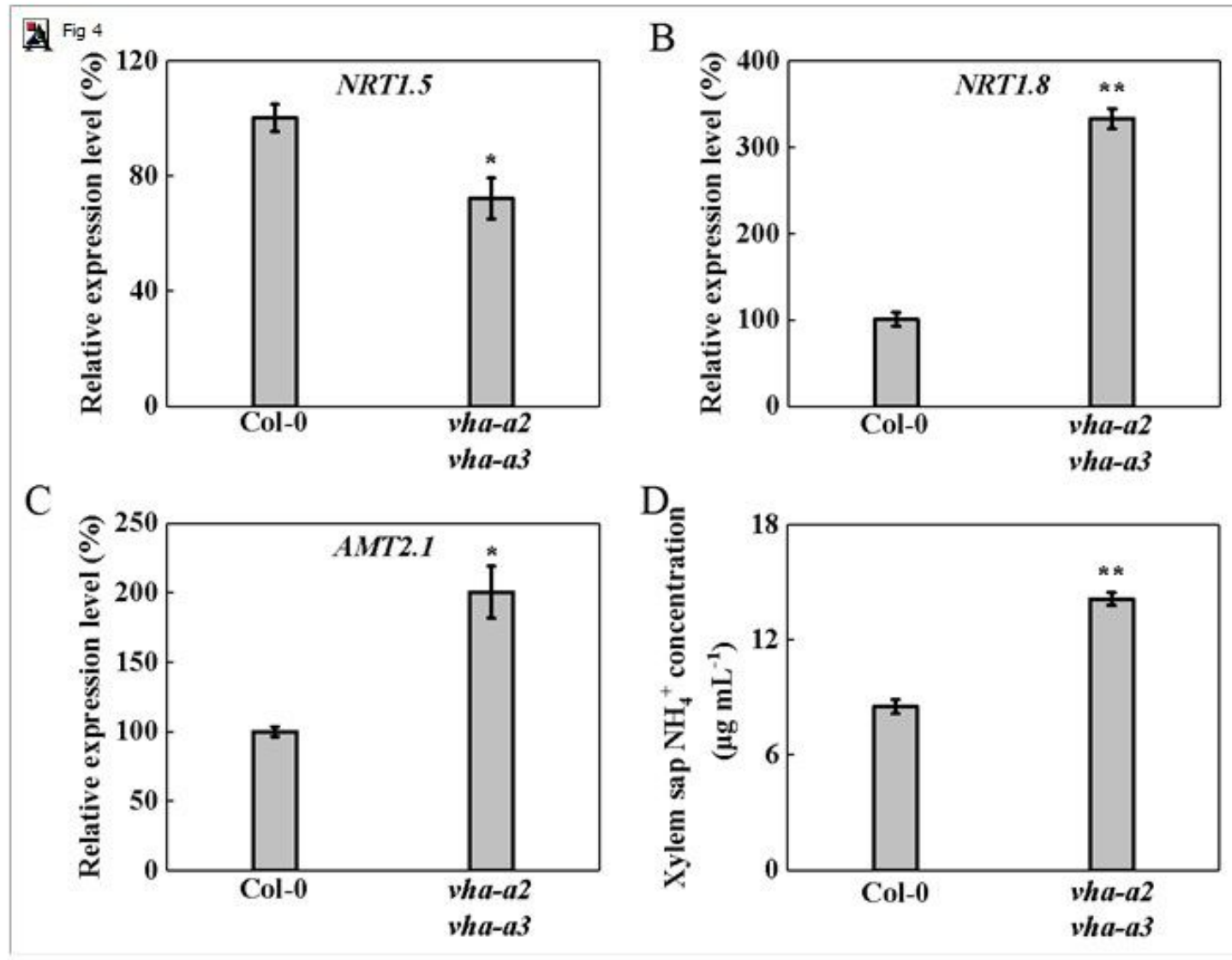

\section{Figure 4}

Nitrogen transport over long distance between shoots and roots. Relative expression levels of NRT1.5 (A), NRT1.8 (B) and AMT2.1 (C) were determined from the roots of wild-type and vha-a2vha-a3 mutant. The wild-type was set to $100 \%$. (D) Higher xylem sap NH4+ concentration in vha-a2vha-a3 mutant. Error bars in $(A)$ to $(C)$ were mean \pm S.E. $(n=3)$ and in $(D)$, mean \pm S.D. $(n=3)$. Asterisks $\left({ }^{*}\right)$ and $\left({ }^{* *}\right)$ indicate significant differences at $p<0.05$ and $p<0.01$, respectively. 


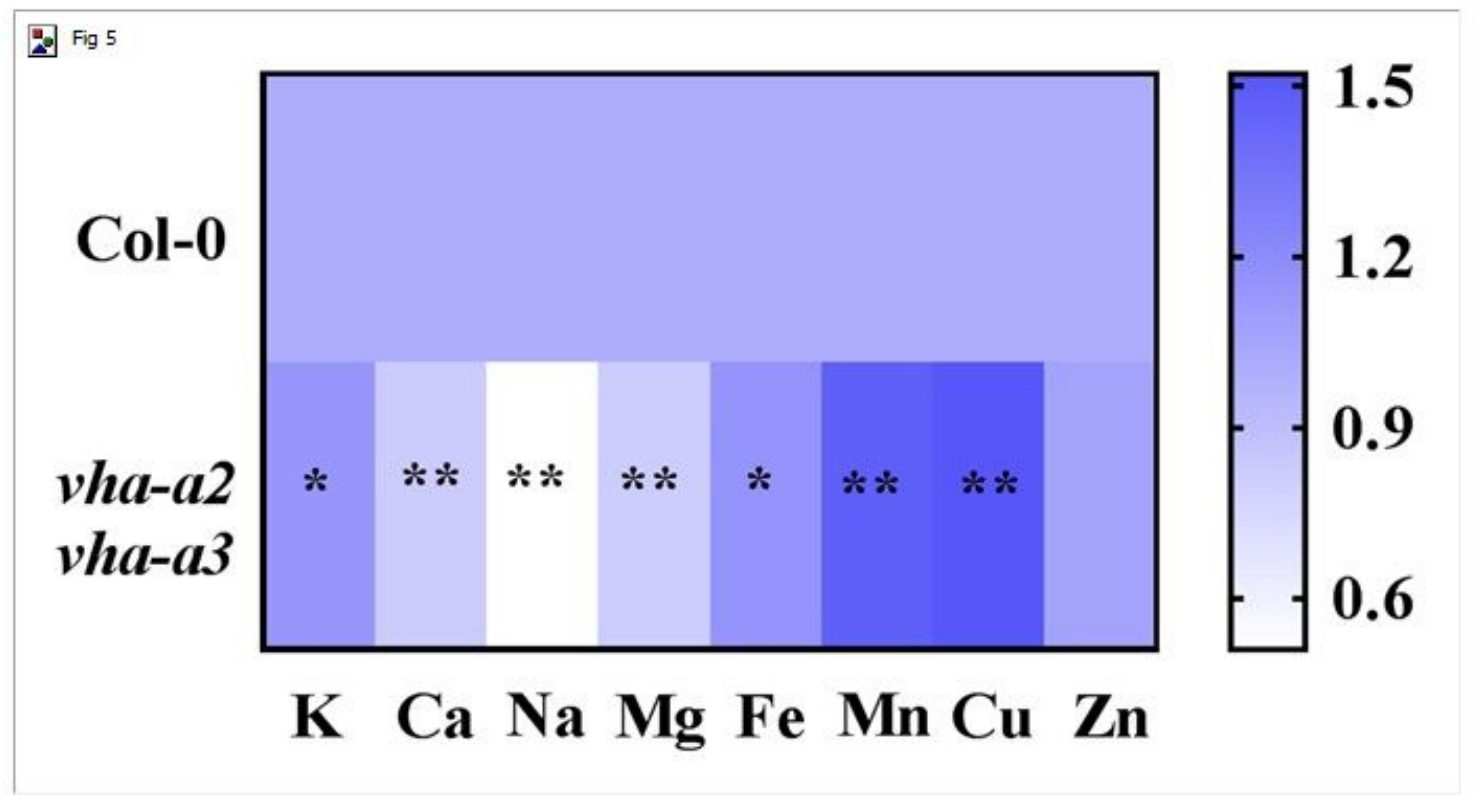

Figure 5

Impaired tonoplast V-ATPase activity prejudiced ion homeostasis. The cationic concentration of $\mathrm{K}+$, $\mathrm{Ca} 2+, \mathrm{Na}+, \mathrm{Mg} 2+, \mathrm{Fe} 2+, \mathrm{Mn} 2+, \mathrm{Cu} 2+$, and $\mathrm{Zn} 2+$ in shoots of wild-type and vha-a2vha-a3 mutant. The wild-type was set to 1.0 and as control. Asterisks $\left({ }^{*}\right)$ and $\left({ }^{* *}\right)$ indicated significant differences at $p<0.05$ and $p<0.01$, respectively. 


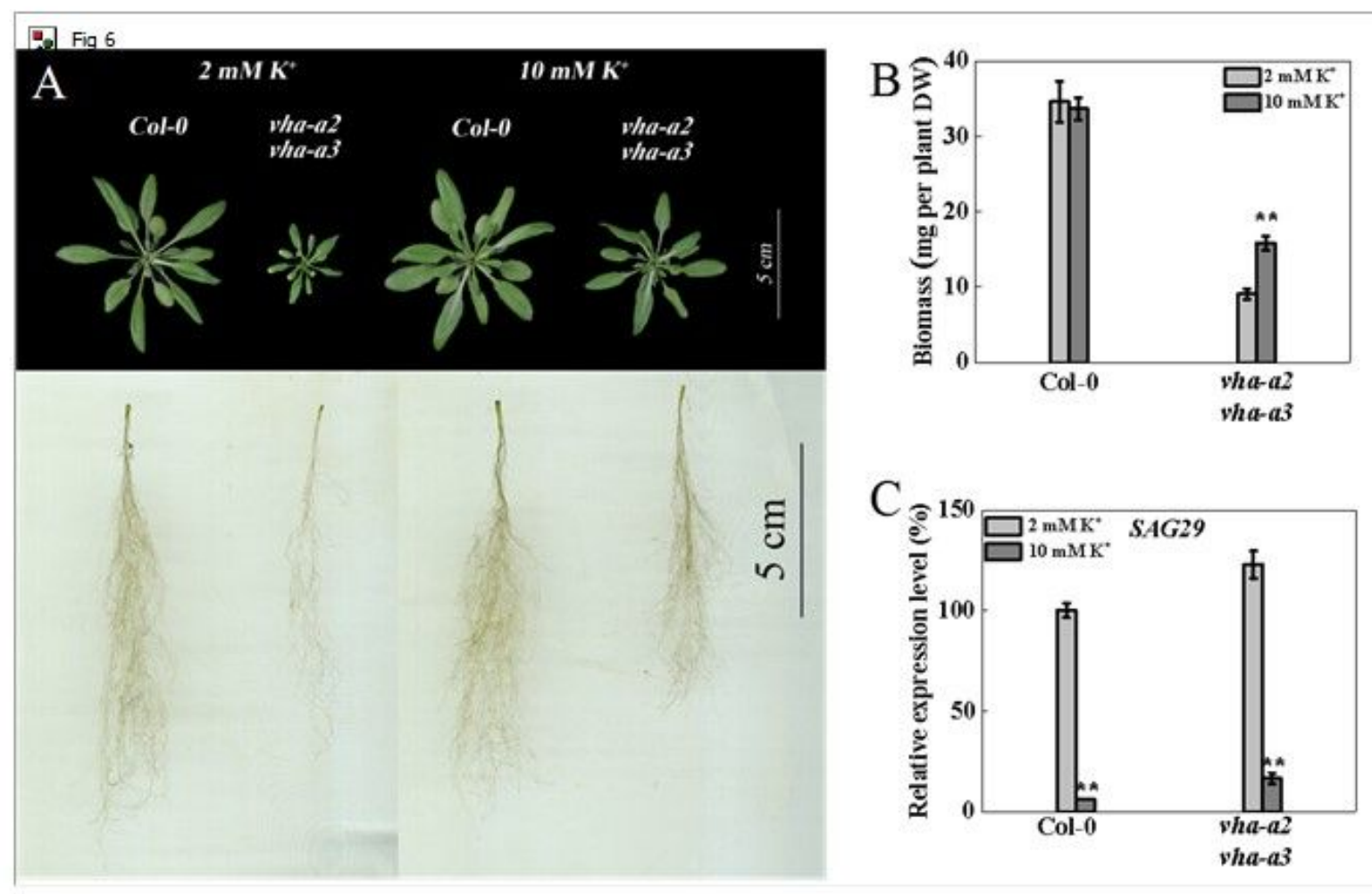

\section{Figure 6}

The growth performance of vha-a2vha-a3 mutant was improved with the additional $\mathrm{K}+$ supplied. (A) The phenotype of wild-type and vha-a2vha-a3 mutant with additional $\mathrm{K}+$ supplied. Pictures show four-weekold plants with different $\mathrm{K}+$ supply levels. (B) The biomass of Col-0 and vha-a2vha-a3 mutant was determined. (C) Gene expression levels of SAG29 in four-week-old leaves of wild-type and vha-a2vha-a3 mutant with different levels of $\mathrm{K}+$. Wild-type with an additional supply of $2 \mathrm{mM} \mathrm{K}+$ was set to $100 \%$ and error bars were defined as S.E. of $n=3$ biological replicates. Pictures show four-week-old plants with different $\mathrm{K}+$ supply levels. Error bars in (B) indicate S.D. of $\mathrm{n}=3$ technical replicates. Asterisks ( $\left.{ }^{\star *}\right)$ indicate significant differences at $p<0.01$. 


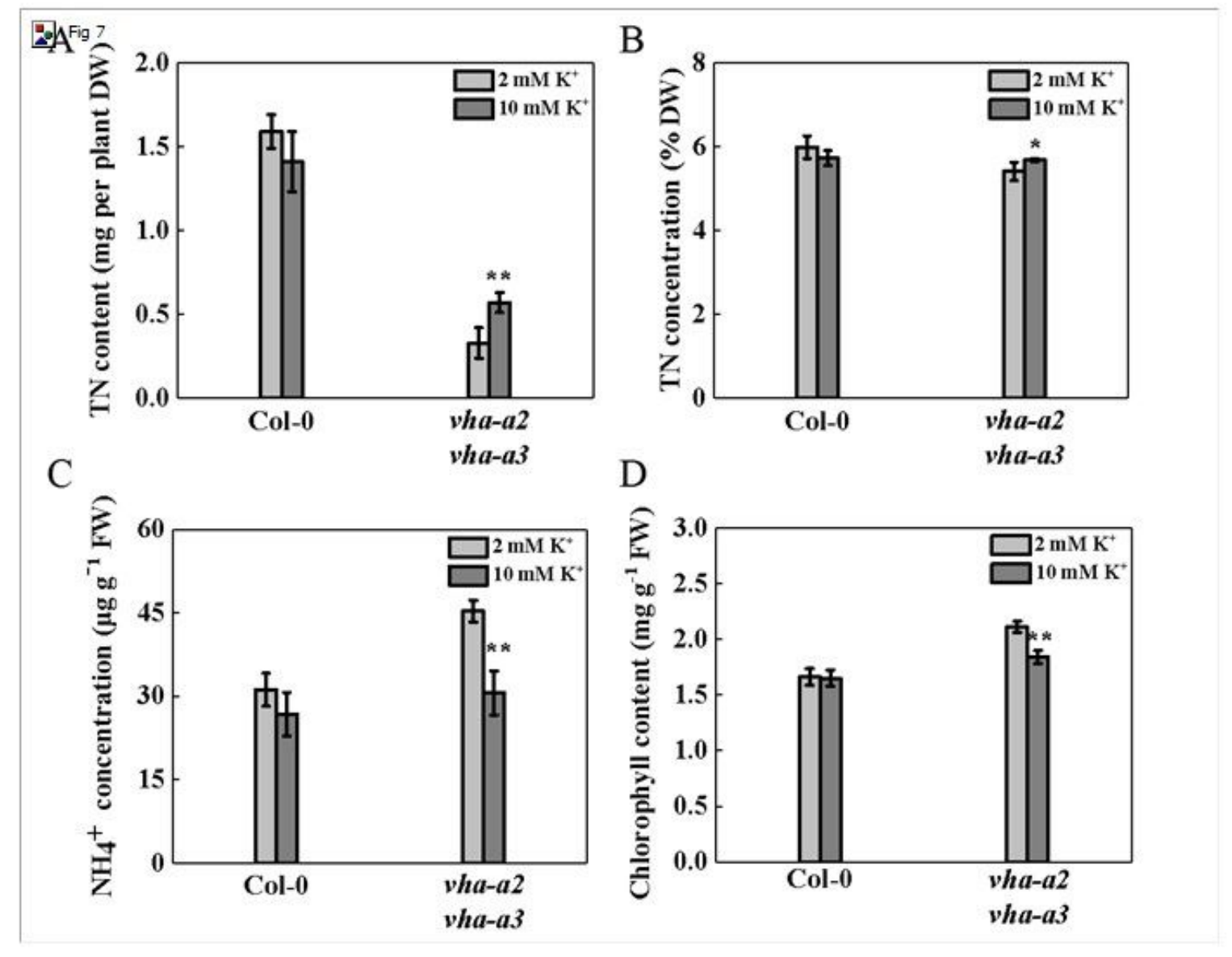

Figure 7

Promotion of nitrogen absorption and reduction of ammonium accumulation with an additional $\mathrm{K}+$ supply in mutant. The TN accumulation (A), TN concentration (B), ammonium concentration (C), and chlorophyll (D) were measured with different $K+$ doses for wild-type and vha-a2vha-a3 mutant grown in hydroponics for four-week-old plants. Error bars indicated S.D. of $n=3$ technical replicates. Asterisks $(*)$ and $(* \star)$ indicate significant differences at $p<0.05$ and $p<0.01$, respectively.

\section{Supplementary Files}

This is a list of supplementary files associated with this preprint. Click to download.

- SupplementalMaterial.doc 